\title{
The Effects of Domestication on the Brain and Behavior of the Chicken in the Light of Evolution
}

\author{
Julia Mehlhorn ${ }^{a}$ Svenja Caspers ${ }^{a, b}$ \\ ${ }^{a}$ Institute for Anatomy I, Medical Faculty, Heinrich-Heine-University Düsseldorf, Düsseldorf, Germany; ${ }^{\mathrm{b}}$ Institute of \\ Neuroscience and Medicine (INM-1), Research Center Jülich, Jülich, Germany
}

\section{Keywords}

Brain - Domestication - Chicken - Breeding · Crested chicken · Laying hen · Artificial selection

\begin{abstract}
The avian class is characterized by particularly strong variability in their domesticated species. With more than 250 breeds and highly efficient commercial lines, domestic chickens represent the outcome of a really long period of artificial selection. One characteristic of domestication is the alterations in brain size and brain composition. The influence of domestication on brain morphology has been reviewed in the past, but mostly with a focus on mammals. Studies on avian species have seldom been taken into account. In this review, we would like to give an overview about the changes and variations in (brain) morphology and behavior in the domestic chicken, taking into consideration the constraints of evolutionary theory and the sense or nonsense of excessive artificial selection.

(c) 2021 The Author(s)

Published by S. Karger AG, Basel
\end{abstract}

We focus on extreme breeding forms like the crested chicken and laying hens to demonstrate the strength of such domestication effects. Discussing domestic chicken

karger@karger.com www.karger.com/bbe

Karger $\stackrel{\text { ' }}{5}$

GOPEN ACCESS
(C) 2021 The Author(s)

Published by S. Karger AG, Basel

This article is licensed under the Creative Commons Attribution 4.0 International License (CC BY) (http://www.karger.com/Services/ OpenAccessLicense). Usage, derivative works and distribution are permitted provided that proper credit is given to the author and the original publisher. breeds representing different selection criteria provides evidence for domestication-induced brain alterations as adaptations to the man-made environment. Domestic chickens are an example of mosaic brain evolution, where the size of different brain structures evolves independently according to differential selective pressures associated with different tasks. Findings about the chicken brain support the hypothesis that domestication reflects a stillongoing accelerated evolutionary process.

\section{Domestication and Evolution}

Domestication leads to a large number of different breeds within different species and still fascinates evolutionary biologists. Research in this field has yielded insights into the rapidity with which selection can alter behavior and (brain) morphology. The influence of domestication on brain morphology has been reviewed in the past, but mostly with a focus on mammals (e.g., Kruska $[1988,2005,2007])$. So far, studies on avian species have seldom been taken into account. The avian brain shows a completely different organization to the mammalian brain. Birds lack a neocortex but have, instead, several large pallial aggregations without apparent laminar structure, and their neuronal density is higher than in mam- 
mals (for review, see Reiner et al. [2004] and Güntürkün and Bugnyar [2016]). Obviously, there are also class-independent trends, and the influence of domestication on brain morphology is similar in bird and mammals. Specifically, many types of fowl have been bred for various purposes. Domestic chicken are generally best used to assess the relationship between brain morphology, avian biology, behavior, and the consequences of domestication. In this review, we would like to give an overview about the changes and variations in (brain) morphology and behavior in the domestic chicken, taking into consideration the constraints of evolutionary theory and the sense or nonsense of excessive artificial selection. We start by giving a general introduction to domestication, its relevance in evolution, and its consequences for (brain) morphology. A description of the effects of domestication on the brain and behavior of the chicken, with a focus on extreme breeding forms, completes the review.

The domestication of animals began 20,000 years ago and can be defined as a recent event in human history in which the breeding, care, and feeding of animals are more or less controlled by man [Hale, 1969; Diamond, 2002]. The first animal to be domesticated was the dog, with the wolf as its wild ancestor [Hemmer, 1983; Clutton-Brock, 1987; Herre and Röhrs, 1990]. With the beginning of agriculture and farming 10,000 years ago in the Middle East, the domestication of animals like cows, pigs, sheep, and poultry began. Since then, two types of breeds (without including pets) arose.

On the one hand, many economic breeds or commercial lines with ever-higher and higher outputs were bred. There is a high yield of meat, milk, wool, and eggs from these animals, which makes them important for the economy and nutrition of the population. On the other hand, we find breeds without this high productivity, bred just for the pleasure of the breeder, and called "fancy breeds." Often, but not always, they originated from traditional farm breeds and the ancestors of commercial strains. Before the development of the economic breeds, these breeds provided farmers with meat, eggs, etc., mainly for personal use.

Determinants for the domestication of a species cover a wide range of factors, such as food resources (seed- or grass-eaters) or the capability of foraging on their own, respectively; the disposition of reproduction in captivity; the capacity for imprinting (important for the habituation to man); and a social structure which allows keeping individuals of these species in large groups and in small spaces [Boice, 1973; Diamond, 2002]. Traits such as docility and fast growth often give way to qualities that benefit humans. Since the common denominator for any successful domestication of animals is an initial reduction in fear of humans, there are theories proposing the evolution of domesticated phenotypes to be driven by the selection of tameness [Belyaev et al., 1985; Agnvall et al., 2017].

For centuries, morphological traits were important for selection by breeders. Subsets of morphological variants were the basis of defining breed standards, based on phenotypic description. Since the 20th century, the quantitative genetics theory (which focuses on the genetic basis of phenotypic variation among the individuals in a population) was applied with high efficiency to breed development, particularly in industrial animal breeding [TixierBoichard et al., 2011]. Clutton-Brock [1987] defined a breed as a group of animals from one species which differs from another group of the same species in typical heritable traits. Such a breed is the product of man's selection. During domestication, many different breeds developed which differ in coloring, size, shape, habitat, or behavior. Besides numerous intraspecies differences, there are also striking convergences and parallel developments in domesticated individuals of different species, including typical modifications in their sexual behavior like reduced mating behavior, the loss of seasonal breeding/reproduction, more frequent estrous cycles, more offspring, or decreased broodiness (in the case of poultry). Another characteristic is the loss of pigmentation and the facilitation of "non-natural" or eye-catching colors, i.e., in wild animals, you rarely find the color white (except in arctic regions, for instance), while depigmentation, light colors, and albinism are found more often in domesticated animals [Belyaev et al., 1985; Herre and Röhrs, 1990; Sheppy, 2011]. Most domestic animals show alterations in body size, with increases more often found in farm animals and decreases more often found in pets (up to gigantism and dwarfism). This ensemble of typical traits in domestic animals could be denominated as the "domestication syndrome" and was already described by Darwin [1868]. Wilkins et al. [2014] proposed that the domestication syndrome results predominantly from mild neural-crest cell deficits during embryonic development. Most of the modified traits, including brain alterations, can be explained as direct or indirect consequences of such deficiencies. Other explanations for the genetic foundations, like single-gene mutants or epigenetic changes, do not mimic the whole domestication syndrome phenotype. However, the precise genetic (and epigenetic) bases of the domestication syndrome require further elucidation.

Beyond all these alterations, domestication usually leads to another specific phenomenon, namely, a reduc- 
tion in brain size compared to their wild ancestors [Herre and Röhrs, 1990]. This phenomenon is based on allometric approaches that take body weight into consideration. The idea is to account for the influence of body weight on brain weight [Snell, 1892; Dubois, 1897; Frick and Nord, 1963; Stephan et al., 1988]. In wild species, however, some data obtained through the allometric method could be better understood as somatization rather than encephalization, e.g., Towe and Mann [1995] and Mann et al. [2018]. Phenomena like this are seldom found, but have led to an intensive discussion of the allometric method in comparative neurobiology (Clutton-Brock and Harvey [1980], Harvey [1988], and Stephan et al. [1988]). Recent studies suggest that, at least in the chicken, the gene loci controlling variations in brain and body mass during domestication have separate genetic architectures and are therefore not directly constrained [Henriksen et al., 2016; Höglund et al., 2020]. This means that it is not necessarily better to rely on relative than absolute brain sizes in correlative studies.

This contrasts with the very large amount of data on insectivores [Stephan et al., 1991], primates [Stephan et al., 1981], and bats [Baron et al., 1996], which deliver a plausible insight into adaptive brain evolution. We subscribe to the argument of Stephan et al. [1991], that a reasonable body weight range (ideally with the factor 10) helps to define a suitable slope and calculate encephalization indices. In this review, we often refer to studies with allometric approaches and data from samples covering a reasonable body weight range and stemming from one biologically significant group, e.g., a taxonomic unit (in our case, the taxon Gallus gallus). Indeed, recent studies show that the role of allometry in determining brain variables should be revised, but its significant influence on brain studies is obvious. Repeated analyses with different methods have even confirmed the original conclusions made from allometric approaches [Finlay et al., 2011; Castiglione et al., 2021]. Taxon-specific brain/body allometry is still widely acknowledged and gives insights into the development of brain (parts) size [Willemet, 2013].

Brain size reduction in domestic animals is typically due to a decrease in total brain size or a reduction in some special brain areas (in relation to body weight) and can be quite pronounced. Domestic pigs show a decrease in relative brain size of $>30 \%$ compared to the wild boar [Kruska and Stephan, 1973]. Similarly distinct is the relative brain size reduction in dogs versus wolves [Weidemann, 1979, Ebinger, 1980]. Even in domestic rats, a decrease in relative brain size of approximately $9 \%$ compared to the wild rat was found [Ebinger, 1972]. The same is true for domestic birds. In poultry, the turkey shows the most pronounced reduction in relative brain size of about $30 \%$, followed by the goose and the duck with approximately $16 \%$, and the pigeon with 7\% [Ebinger and Löhmer, 1984, 1987; Rehkämper et al., 1988; Ebinger, 1995].

This decrease is not uniform but varies in different species and in different brain parts. Generally, reduction is most pronounced in the telencephalon, followed by the diencephalon and cerebellum. In the telencephalon, structures of the visual, olfactory, limbic, and trigeminal systems are more affected than other structures [Kruska, 1972; Herre and Röhrs, 1990; Ebinger, 1996]. The large phenotypic variability in domestic animals is also evident in their brain composition. Here, there are even intrabreed-specific differences, with different breeds showing different sizes in their brain structures. Möller [1975], Haase et al. [1977], Bronson [1979], Rehkämper et al. [1988], and Augustyniak-Perko et al. [1996] were the first to publish data identifying breed-typical brain characteristics in domesticated species. Interestingly, feral mammalian domesticates retain their small brains after as many as 40 generations of being back in the wild [Kruska, 2005]. This argues for the assumption that smaller brains became hereditary in domestic animals. Generally, it has been shown that the size of brain structures is heritable and controlled by independent loci [Airey et al., 2000; Hager et al., 2012].

Three components determine the type and extent of reduction in brain size in domestic animals compared to their wild ancestors: (a) the level of cerebralization of the ancestor (higher encephalized animals show greater reductions in brain size), (b) the duration of domestication (animals domesticated longer show greater reductions in brain size), and (c) the intensity of keeping and breeding (more intensive keeping and breeding leads to greater reductions in brain size) [Hemmer, 1983; Herre and Röhrs, 1990; Ebinger, 1996].

The relationship between domestication and evolution is still a matter of discussion, but the fact that domestication is a process with clear and dramatic evolutionary impact cannot be ignored. It has created new organisms that live best in a man-made environment, transformed landscapes, and reshaped the trajectory of human cultural evolution [Zeder, 2018]. Domestication can be regarded as a model system for exploring evolutionary theories like "extended evolutionary synthesis" (EES), which suggests that not just selection but also reciprocal causation, developmental processes, and inheritance act as drivers for evolutionary change [Zeder, 2017, 2018]. Experiences 
and interactions with the environment (which include man as a selecting factor) play a significant role [Price, $1999,2002]$. Several hypotheses try to explain these complex interactions, i.e., the "regression hypothesis" and "adaptation hypothesis." According to the regression hypothesis, domestication is seen as a "decline of environmental appreciation" leading to a reduction in behavioral patterns (like the lack of dabbling in ducks, a behavioral pattern that lost its value during domestication) and, finally, to a reduction in brain size [Hemmer, 1983]. The adaptation hypothesis refers to domestication as a dynamic evolutionary process, with all alterations during domestication having an adaptive character due to the changed conditions of a man-made environment [Rehkämper et al., 1988, 2008]. Therefore, the reduction in brain size is not a regrettable degeneration, but rather an optimal adaptation to the actual conditions. Large brains are energetically expensive, and in circumstances in which selective pressure is relaxed, e.g., in a man-made environment, selection is for smaller brains [Castiglione et al., 2021]. Given the worldwide distribution and numbers of domestic animals, there is no doubt that they are very successful in their ecological niche (man-made). Thus, domestication should not be seen as a degradation process, but might be better defined as a special kind of evolution which is driven by artificial or combined artificial-natural rather than pure natural selection, and results in adaptation to a man-made environment. This is in line with a third hypothesis which suggests that an initial reduction in fear of humans was of central relevance for the beginning of domestication [Agnvall et al., 2017]. A reduced brain size evolved as a related secondary effect of this and may be adaptive (see the section Comparisons with the Red Junglefowl for more details).

Finally, domestication could be called a big biological experiment which gave rise to the occurrence of domestic animals or pets from wild animals. The aim of this review is to discuss domestication as an evolutionary process (referred to above) and to introduce domestic chicken breeds as representative of different selection criteria.

\section{Domestication of the Chicken}

The avian class is characterized by particularly strong variability in the domesticated species. Presumably, the domestication of birds or poultry began 4,500 years ago with the grey goose, followed by the chicken [Sossinka, 1982]. Since fossils are rare and distinguishing fossils of wild from domesticated poultry is difficult, the exact timepoint is ambiguous. Domestic fowl, or chickens, are kept throughout the world and are the most widely used of all poultry species. Although four living wild Gallus spp. are known (G. gallus, G. sonneratii, G. varius, and $G$. lafayettii), the domestic chicken is considered to have originated mainly from the Red Junglefowl (G. gallus) [Fumihito et al., 1996; Miao et al., 2013]. On the basis of morphology and protein polymorphism, G. gallus is considered to be the closest relative to the domestic chicken. G. gallus give fertile offspring after crossing with domestic chickens, confirming, according to Mayr [1963], that they belong to the same species. A combination of archeological, morphological, and molecular data have revealed three major facets of poultry domestication: (a) domestication probably occurred independently at different locations in Asia, (b) the yellow skin trait (originating from G. sonneratii) suggested a hybrid origin of the domestic chicken, and (c) gene flow between wild jungle fowl and village chickens still takes place in some regions of SouthEast Asia, showing that domestication is still an ongoing process [Tixier-Boichard et al., 2011]. The fowl was mainly domesticated for two reasons: for use in agricultural or manufactured products and for aesthetic reasons or companionship. Chickens are also thought to have been used as religious symbols, for ceremonial purposes, and cultural activities. These factors, their pleasing appearance, and special behavioral features like the fighting abilities of cocks might be of even higher importance for domestication than expected [Komiyama et al, 2003; Mehlhorn and Rehkämper, 2013]. It is possible to differentiate between commercial breeds (or strains) and noncommercial, so-called fancy breeds. Commercial breeds are divided into layer breeds, meat breeds, and dual-purpose breeds. In commercial strains (genetic), variability is low; in fancy breeds, we find greater genetic, morphological, and behavioral variability. Often, fancy breeds have their origin in traditional farm breeds, but there are also breeds which never had economic importance (e.g., the crested chicken). Great variations in size, shape, color, feather structure, and behavior exist among fancy poultry breeds. There are breeds with morphological features like dwarfism, gigantism, shortened legs, rumplessness, an absent or enlarged comb, etc. A lot of breeds show alterations of feathering like curly feathers, feather crests, foot-feathering, elongated tail feathers, or the loss of feathers in the head and/or neck region. There are also breeds with peculiarities in behavior (breeds without broodiness, fighting/game breeds, or breeds with special crowing behavior). Additionally, all these breeds occur in many different colors, a typical phenomenon of domestication 







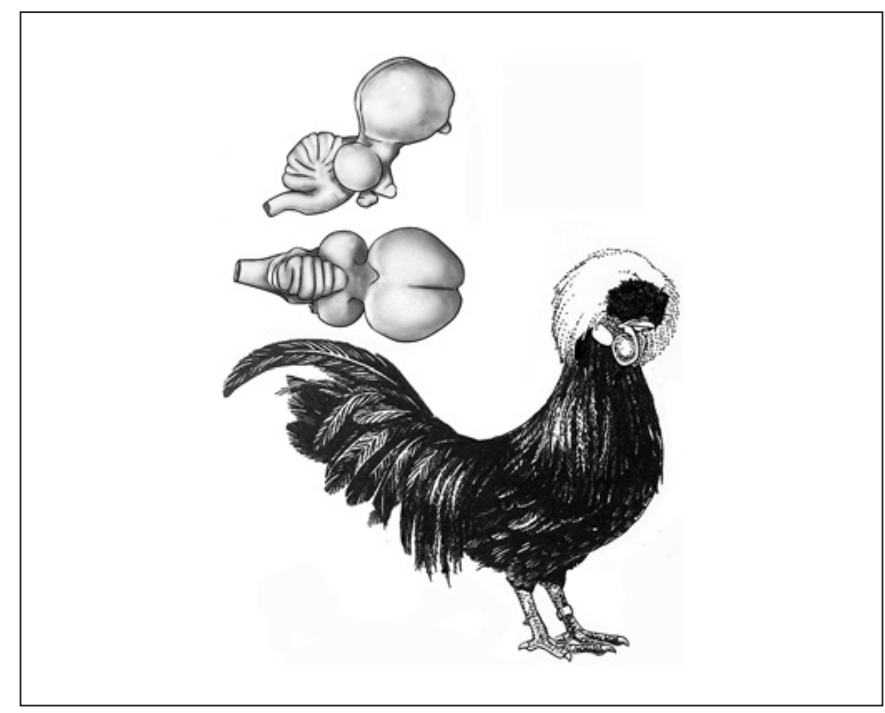

Fig. 1. Habitus and brain (above: sagittal view, below: dorsal view) of a cock of the White Crested Polish breed. A typical characteristic is the feather crest which is situated on a bony protuberance of frontal bones. The brain is relatively enlarged; the forebrain and hindbrain seem to be more separated from each other.

[Sheppy, 2011]. In terms of zoological nomenclature, we regard them as subspecies, representing "intraspecies" variability. Subspecies are often seen as progressing towards new species and reflect morphological, physiological as well as ethological variability [Coyne and Orr, 2004]. Relevant ethological data are laboriously obtained and are thus quite rare. Morphological data are typically easier to obtain and could possibly help to identify strains or breeds of a domestic species that might be worthy of preferential ethological investigation. To illustrate the effects of domestication on brain morphology and to reveal peculiarities due to domestication, we present insights into several chicken breeds, laying hens, and their wild ancestor, the Red Junglefowl. We focus on extreme breeding forms to demonstrate the potential large effect on size that domestication can infer. Extreme breeding forms could also serve as model organisms for diseases or defect mutants (see below). Table 1 summarizes the domestic chicken breeds described as well as their typical/modified traits.

\section{Crested Chicken}

Elongated feathers on the head are a common feature among birds and can be found in the Grey Crowned Crane (Balearica regulorum), the White Cockatoo (Caca-

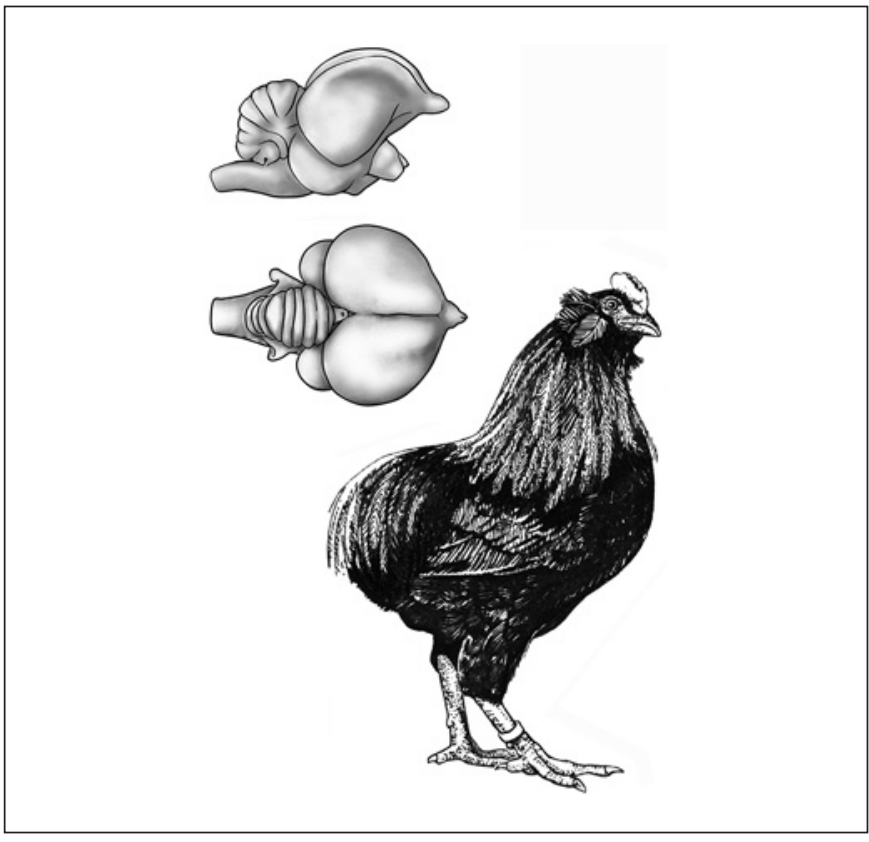

Fig. 2. Habitus and brain (above: sagittal view, below: dorsal view) of a cock of the Araucana breed. Typical characteristic are ear-tufts (feather-covered epidermal appendages in the ear area) and the lack of free caudal vertebrae ("rumplessness").

tua alba), or the Crested Lark (Galerida crestata). The propensity to develop a crest is also present in domesticated birds. Crests are known to occur in breeds of chickens, ducks, pigeons, geese, and even in canaries and budgerigars. In chickens, a fully developed crest is typical of several breeds, including Houdans, White Crested Polish (WCP), and Padovana. Crested chickens are characterized by an autosomal mutation $(\mathrm{Cr})$ that promotes the development of elongated feathers on the cranial skin that sprout from the head, shaping the tuft (genomic sequence HOXC8) [Wang et al., 2012]. The crest shows an autosomal incompletely dominant mode of inheritance. It is associated with cerebral hernia (he), that gives rise to a malformation of the skull consisting of a bony protuberance in which the hernia is located [Yoshimura et al., 2012].

The best-studied example of a crested chicken is the WCP (Fig. 1). WCPs have one of the longest histories of pure breeding among chickens and are special in many more aspects than just their appearance (see below) [Brothwell, 1979]. The feather crest on the head is placed on a bony protuberance of frontal bones. This protuberance is, typically, not completely calcified, and if it is very distinct, can be compared to that of a human exencephalocele. As mentioned above, the external morphology of the brain under the distinctively shaped skull is different 


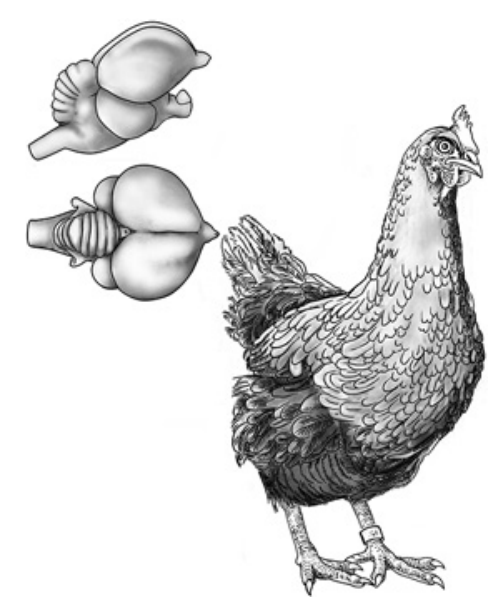

Fig. 3. Habitus and brain (above: sagittal view, below: dorsal view) of a laying hen (a Brown Leghorn). Laying hens can lay up to 320 eggs per year. They have significantly smaller brains than other chicken breeds.

from that of other chicken breeds (Fig. 1-3). The forebrain and hindbrain seem to be more separated from each other and the cerebral hemispheres are extruded into the spherical region of the skull. This morphological character is often called "cerebral hernia" [Brothwell, 1979]. The protuberance is the result of adaptation to encephalic conformation [Frahm and Rehkämper, 1998a].

A bony protuberance seems to be characteristic in crested chickens, as it is also observed in the Padovana [Verdiglione and Rizzi, 2018], a local breed in Veneto, a region in northeast Italy, and characterized by a big tuft rising from a very pronounced bony hemispherical protuberance. The surface of the bony protuberance is, as in the WCP, not continuous, but interrupted by openings (variable in number and dimensions). To date, there are no brain data on the Padovana chicken, but the skull anatomy shows that the height of the skull and the ratio between the frontal bone and width of the skull is greater than in the uncrested chicken [Verdiglione and Rizzi, 2018]. However, the anatomical and physiological significance of cranial openings, or, what seems to be much more important, the consequences for brain function, is still unknown. In some individuals, only one big opening at the top of the skull can be observed. This seems to be similar to the Crested Duck [Cnotka et al., 2007]. Here, the crest is situated in the parietal part of the skull on a cushion of fat and connective tissue. Often the cranium under the crest is open, and Crested Ducks, like WCP, often show enlarged ventricles [Mehlhorn and Rehkaem-

Brain and Behavior in the Domestic Chicken per, 2010]. In Crested Ducks, this is due to breed-specific intracranial fat bodies, which, depending on their size, can alter brain composition and interfere with the flow of cerebrospinal fluid [Cnotka et al., 2008].

By comparing the brain morphology of several chicken breeds, it has been shown that the increased variability in domestic chicken breeds is reflected in their brain composition [Frahm and Rehkämper, 1998a; Rehkämper et al., 2003]. Allometric comparisons, i.e., studying the influence of body weight on brain size, and cluster analysis revealed that there are intraspecies differences in relative brain size and composition, with crested chicken breeds (e.g., Kraaikoppen, WCP), particularly, standing out. In detail, the brain of the WCP is relatively larger, partly due to the enlarged ventricles observable in most, although not all, individuals. Additionally, the optic tract, diencephalon, hyperpallium apicale and densocellulare, mesopallium, and nidopallium are significantly enlarged in this breed [Frahm and Rehkämper, 1998a]. Most of these structures are associated with cognitive abilities. This is particularly interesting because, to date, it is unknown if the enlarged brains of WCP are accompanied by a respective gain in function. To date, behavioral studies have not been able to show an advantage in cognitive or learning behavior [Tiemann and Rehkämper, 2007].

The differences in appearance, brain size, and brain composition between WCP and other breeds is as large as interspecies differences could be. Thus, WCP might be a model for testing if speciation occurs under the conditions of domestication. According to Price [1999, 2002], domestication also involves genotypic adaptation. Thus, in the process of domestication, there is also the chance that new species develop, since new species are distinguished from older ones by alterations in gene frequencies and the consequences thereof [Wright, 1978]. Therefore, domesticated animals are good models for studying speciation. This is particularly true because an investigation of selective criteria is easier within the constraints of domestication than in the wild.

One reason that WCP might be on the way to become a new species, is their outstanding brain composition in comparison to other chicken breeds (see above and Rehkämper et al. [2003]). Another argument can be found in their mating behavior. Sexually mature female WCP have a statistically significant preference for males of their own breed even if a male of another breed is presented simultaneously [Tiemann and Rehkämper, 2009]. This indicates the beginning of a sexual isolation which is a precondition of speciation [Rensch, 1929; Mayr, 1963]; the authors concluded that WCP might be "on the way" to 
becoming its own species. This is supported by the fact that WCPs tend to flock together, as shown by shorter interindividual distances between WCPs than between WCPs and other chicken breeds [Tiemann and Rehkämper, 2008]. Another study even showed that number of purely WCP offspring is higher than those of WCP and other chicken breeds [Tiemann and Rehkämper, 2012]. Due to selection and mate choice, it seems to be that breeding, in principle, can generate new species. Of course, WCP can still have fertile offspring with other chickens, but there are many varieties of speciation, isolating barriers, and selection mechanisms below the level of infertile pairings [Coyne and Orr, 2004].

Not all alterations in external (head) morphology must alter brain morphology. The breed Araucana (Fig. 2), originally from Chile, is a multipurpose breed initially established for its blue-shelled eggs [Ekarius, 2007]. Another characteristic is the so-called ear-tufts. These are feather-covered epidermal appendages or peduncles which protrude from the sides of the head in the general area of the ear. These ear-tufts are associated with an irregular external ear opening, a reduced external auditory canal, and a reduced middle-ear fossa. An incomplete and abnormally positioned hyoid apparatus and clefts and furrows near the peduncle and neck area are other structural abnormalities [Pabilonia and Somes, 1983], believed to be due to the early incomplete fusion of the hyoid and mandibular arches from the distal part of the ear opening to the neck area. It was speculated that hearing might be negatively influenced by these morphological phenomena but, to date, there are no studies on hearing in Araucanas. However, Frahm and Rehkämper [1998b] showed that these alterations are at least not correlated with alterations in the brain. Allometric comparison reveals no reduction in size of the angular, laminar, and superior olivary nuclei (all involved in hearing) in Araucanas compared to Japanese Bantams and Brown Leghorns. There is, however, a slight increase in the size of the magnocellular nuclei which receive direct projections from the cochlear and lagenal nerves and are involved in directional hearing and processing auditory information for spatial localization [Frahm and Rehkämper, 1998b].

The loss of feathers in the head and/or neck region is another example of alterations of feathering in chicken breeds. Fighting and game cocks like the Japanese "Shamo" are (still) found all over the world. They are selectively bred for their muscular and wide bodies, long and strong legs, and aggressive nature. Their plumage is extremely reduced to minimize the contact surface, and the head, neck, and breast are nearly nude. There is hardly anything known about their brains, but Komiyama et al. [2020] recently showed that their aggressiveness has resulted from a combination of naturally inherited and mutant genes derived by artificial selection. Shamo game cocks exhibit higher midbrain levels of norepinephrine than laying hens, and gene mutations which are potentially associated with fighting behavior and originated via artificial selection [Komiyama et al., 2020]. The brain of another game cock breed, the "Malayan," is included in the study on brain composition in different chicken breeds [Rehkämper et al., 2003], but Malayan brains did not show any specifics.

\section{Laying Hens}

Next to fancy breeds are commercial chicken breeds, with laying hens (Fig. 3) being the best studied. The first difference between the commercial and fancy breeds is that, in the former, closely related strains or lines are differentiated rather than breeds. These lines show lower variability in phenotype and genotype due to purer breeding. In layer lines, pure breeding, or even inbreeding, over a long period of time has led to strains with a laying performance of approximately 320 eggs per year (the Red Junglefowl, the wild ancestor of domestic chickens, usually lays just two clutches per year, of 8-10 eggs). Generally, these strains all originated from a small parental generation. It is well established that inbreeding diminishes the physiological and reproductive performance of most organisms and reduces fitness in general [Charlesworth and Willis, 2009]. On the other hand, systematically controlled inbreeding is a powerful tool to reach a given aim within a few generations. To date, its effect on brain morphology has not been investigated and little is known about the brain of laying hens. Numerous studies exist about productivity and physiology or the behavior of laying hens, but there are only a few studies on their brain morphology. This is the same for broilers. Broiler chickens have been consciously selected for their large body size, relatively large pectoral muscles, rapid growth, and high feeding efficiency. Jackson and Diamond [1996] showed that broilers have smaller brains than Red Junglefowl (as well as longer, wider, and heavier intestines). There is only one study that describes the macroscopic and microscopic morphology of broiler brains [Gupta et al., 2016]; however, this study was mainly descriptive in nature, with no quantitative comparisons with other chickens.

Mehlhorn and Petow [2020] compared two lines of laying hens with seven fancy chicken breeds. In an allo- 
metric approach, it was shown that laying hens had significantly smaller brains than fancy breeds. It seems to be that the brain size of laying hens is at the lower end amongst chicken breeds, thus representing the result of very intensive artificial selection. Apparently, pure breeding over a long time and strong artificial selection for a high production of eggs seems to be accompanied by (an unintentional) selection for smaller brains. Selection for egg production seems to be associated with a decrease in the size of other organs, such as the brain, which is not essential for greater egg production. This is in line with findings about different lines of laying hens. The authors also compared the brains of so-called "high performers" that lay approximately 320 eggs per year with a low-performing line (an average laying performance of 200 eggs per year) which has not been bred further for laying performance since the 1970s. The "low performer" breed had a larger brain, possibly indicating that stronger selection for laying performance is accompanied by a smaller brain. The brain is an organ with a high energy demand and may therefore have become reduced in size as a trade-off for other physiological traits. Whether this reduction in brain size has functional consequences has still to be investigated.

There are several studies which deal with the behavior of laying hens. On the one hand, such studies are intended to help to increase egg production, and on the other, to deal with undesirable side effects (like feather-pecking, cannibalism, etc.) which have arisen with the establishment of alternative housing systems such as floor-housing or free-range housing. Much research has focused on how chickens behave and perform in different housing systems [Whitehead, 2004; Lay et al., 2011; Weeks et al., 2016; Eusemann et al., 2018]. Although modern housing systems such as floor-housing or free-range housing are thought to allow more species-appropriate behavior, with environmental complexity increasing behavioral opportunities, these studies report an increase in patterns of behavior that can be detrimental to the hens' welfare (e.g., feather-pecking) and higher mortality rates (due to cannibalism). Difficulties also arise in terms of disease and pest control. Multiple factors such as disease, skeletal and food health, pest and parasite load, behavior, stress, affective states, nutrition, and genetics can influence animal welfare. Each system bears unique challenges, without one housing system being ideal from the perspective of laying hens' welfare [Lay et al., 2011].

The strong selection of chickens for production traits such as egg-laying is thought to have caused the abovementioned side effects and changes in behavior. Energy

Brain and Behavior in the Domestic Chicken expenditure may also be redirected away from specific behavioral traits to sustain the energy costs of greater egg production, and such energy trade-offs may change the cognitive abilities of these hens [Dudde et al., 2018]. This could be reflected morphologically as smaller brain volumes and is in line with the finding of smaller brains in laying hens [Mehlhorn and Petow, 2020]. This could be a reason why such hens have difficulty adapting to these new housing systems.

It is known that housing conditions, or environmental complexity, can affect the morphology, neurochemistry, and physiology of the central nervous system [Rosenzweig and Bennett, 1996; Diamond, 2001; Mohammed et al., 2002; Rosenzweig, 2003]. Several studies have shown an influence of housing systems on spatial-learning ability behaviors and levels of working memory in laying hens [Krause et al., 2008; Campbell et al., 2018, 2019; Dudde et al., 2018]. In addition, different housing environments can also be accompanied by variations in the brains of laying hens, such as in the hippocampus and the nidopallium caudolaterale [Patzke et al., 2009]. Hens in free-range systems develop larger cells in the dorsomedial hippocampus, exhibit an asymmetry in the tyrosine hydroxylase density, and more fibers in the left dorsomedial hippocampus. In the nidopallium caudolaterale, the housing system affects the serotonergic innervation pattern with the highest fiber densities being found in freerange hens. Mehlhorn and Petow [2020] showed such a correlation between housing conditions and brain morphology as well. Floor-housed hens have a significantly larger cerebellum than cage-housed hens. This could be explained by the limited space in the cages and thus an unchallenged cerebellum as one of the key players in movement control [Ito, 1984]. These findings support the idea that there are external parameters that correlate with quantitative brain composition, with the inherent assumption that measuring brain and brain-part size may be useful as potential readouts for animal welfare [Nordquist et al., 2013]. Another external parameter is the rearing conditions. Rearing conditions have a major effect on behavioral development and social behavior [Rodenburg et al., 2008], and rearing with a foster hen is associated with morphological changes such as differences in cell soma size in the hippocampus of the adult hen's brain [Nordquist et al., 2013]. Rearing with a foster hen or dark breeder rearing also influence the hypothalamic dopaminergic and vasotinergic system and the level of corticosterone in the feathers [Hewlett et al., 2014; Nordquist et al., 2020]. However, to date, little is known about the influence of rearing conditions on the brain plasticity of 
adult hens. There is a demand for research in this field, important for a comprehensive analysis of the brain and behavior of laying hens.

\section{Comparisons to the Red Junglefowl}

Unfortunately, there are no studies on the detailed brain morphology of the Red Junglefowl. This would be useful for comparative studies and a reliable judgement of domestication-associated changes. One reason might be that it is difficult to get purebred Red Junglefowl. These chickens can still be found in Asia, but mostly as a hybrid of wild jungle fowl and village chickens. There are also likely more chicken species included in the domestic chicken than only the Red Junglefowl (see above). It is easier to get captive-bred specimens, but these may not truly reflect the ancestral state. Thus, direct comparisons between the wild and domestic chicken are difficult and rare. Nevertheless, Kawabe et al. [2017] described comparisons of the brain shapes of (presumed) wild and domestic chicken. The shape of the Red Junglefowl brain was clearly different from that of domestic fowl, even when the effect of size was eliminated. Multivariate analyses indicated that Red Junglefowl have a relatively large telencephalon and optic tectum, which might inherently define their brain shape. The relative brain volume was also distinctly larger in the Red Junglefowl than in domestic fowl. There are no studies about the brain composition of Red Junglefowl. Interestingly, the brain shape of small and large domestic chicken breeds differs. The brains of dwarf domestic fowl exhibit more anteroposterior shortening, lateral expansion, and rounding of the brain shape [Kawabe et al., 2017; Stange et al., 2018]. Stange et al. [2018] quantified variations in skull morphology in chickens and compared these to wild fowl using 3-dimensional geometric morphometrics and multivariate statistics. They confirmed that domestic chickens exhibit greater variations in skull shape than their ancestors. Bantams are closest to wild fowl when relating size and brain shape, while fancy Swiss breeds and crested chicken like the WCP deviate from the common shape-size trajectory of fowl and chickens by having a different intercept, irrespective of breed type (e.g., meat, egg, fighting types). Jackson and Diamond [1996] investigated the brain mass of Red Junglefowl and compared it to that of the broiler chicken. They revealed that broiler chickens have relatively longer and wider (hence heavier) small intestines and gut compartments. Offsetting this, they have relatively smaller brains and leg bones than Red Junglefowl.
As mentioned above, understanding the genetic architecture of quantitative variation in brain size is pertinent to determining brain size relations. Henriksen et al. [2016] could show that the gene loci responsible for increasing brain size are distinct from those for increasing body size during domestication. This refutes the classical concept of determining relative brain size (i.e., proportional to body size) as a basis for evolutionary studies. They also showed that, in the chicken, domestication has led to a greater body mass, and, to a lesser extent, a greater absolute brain mass, mainly due to the enlargement of the cerebellum. The authors suggest that brain mass has been altered less by selection during domestication than body mass, and that, in chickens, reduced relative brain mass during domestication may have been caused by an increase in body mass.

Red Junglefowl individuals were also used to investigate the question whether the typical traits of domesticated animals (alterations in reproduction capacity, growth, coloration, and organ size) are associated with tameness [Agnvall et al., 2017]. If Red Junglefowl were selected for high levels of fear of humans, their relative brain weight was larger than in those individuals selected for less fear of humans. It was the same with relative telencephalon weight and the weight of other organs like heart, liver, testes and spleen [Agnvall et al., 2017]. It seems that the size of the brain (and other vital organs) change during domestication as a result of selection for reduced fear of humans. This supports the idea that the common denominator for any successful domestication is an initial reduction in fear of humans. Reduced fear of humans is of central relevance for the initial phases of domestication, with reduced brain size evolving as a correlated secondary effect of this. This size reduction may be adaptive and may affect specific brain functions. Agnvall et al. [2017] also showed that the relative telencephalon size of animals with less fear is smaller, but their cerebellum is larger. This is an example for mosaic evolution under domestication and is consistent with both the "adaptation hypothesis" [Rehkämper et al. 2008] and the "resource allocation theory" which states that animals adaptively allocate resources to different biological functions in relation to the demands of their specific ecological niche, which, in the case of domesticated animals, would be a man-made environment [Beilharz and Nitter, 1998]. Reduced telencephalon size might correlate with reduced learning abilities, perhaps enforced by the reduced environmental complexity of the captive environment. The increase in relative cerebellum size may be related to modifications in reproductive behavior [Agnvall et al., 2017]. 
A large brain with higher cognitive ability may be of higher fitness value in the wild, where obtaining food is difficult and predation is a constant risk. The differences in lifestyle between domesticated animals and their ancestors in terms of the challenges of survival and regarding reproduction could be the explanation for the reduction in the size of brain parts of domestic animals [Diamond, 2002]. The brain requires a lot of energy and may therefore be reduced as a trade-off for other physiological traits, such as reproduction and growth. Agnvall et al. [2017] suggest that the genetic underpinning of brain size may, in fact, be partly associated with genes affecting fearrelated behavior. Brain size changing as a result of selection for reduced fear of humans might be caused by pleiotropy and linkage of involved genes, and this allows adaptations to the "human niche." The domesticated phenotype may be driven by increased tameness.

\section{Potential Drawbacks of Domestication}

In the wild, an animal population may appear relatively homogeneous because of a more or less balanced gene pool; this gene pool may, however, bear many hidden (recessive) alleles. This, together with mutation, recombination, and the phenomenon of genetic drift (also known as the Sewall-Wright effect) is the substrate for a variability that has been identified as one of the most important sources of evolutionary change [Mayr, 1963; Barton et al., 2007]. Genetic drift is the change in the frequency of existing alleles in a population due to random sampling of organisms. It causes initially rare alleles to become much more frequent and even fixed, e.g., if a subpopulation becomes isolated [Wang et al., 2016]. Then, the frequency of single alleles increases rapidly, and special phenotypes are seen regularly. If these are advantageous, they will have a future, perhaps representing the dawn of a new species [Coyne and Orr, 2004]. This type of evolutionary change can be investigated more easily within the constraints of domestication than in the wild. Domestication, though, has dramatically altered the phenotypes of animals due to selection for different traits chosen by humans. One common morphological effect seen in many different species is changes in brain size and brain composition. Chickens are an example as we have shown in this review.

The costs of domestication are an elevated number of harmful or even lethal mutations in the genomes of the domestic lineages compared to their wild ancestors [Bosse, 2019]. The reason for these costs is reduced effi-

Brain and Behavior in the Domestic Chicken ciency of selection against mildly deleterious alleles. Thus, brain size reduction can be an adverse consequence of accidentally breeding in mildly deleterious alleles. Inbreeding and the loss of potentially beneficial alleles due to gene drift can cause problems in the long term for populations that experienced a bottleneck at some point in their demographic history. Moreover, harmful mutations have a chance to rise to higher frequencies through drift [Lynch et al., 2016; Simons and Sella, 2016]. Domestication has often occurred over long periods, with extensive gene flow between wild and domestic populations [Frantz et al., 2015]. However, lower genetic diversity and higher mutational load was observed in domestic populations. In chickens, this is most clearly seen in the layer lines, particularly the White Leghorn breed [Bosse, 2019]. Breed utilization, genetic improvement, and industry consolidation are predicted to have a major impact on the genetic composition of commercial chickens [Muir et al., 2008]; $\geq 50 \%$ of the genetic diversity in ancestral breeds is absent in commercial pure lines. This missing genetic diversity has resulted from the limited number of strains or breeds incorporated. Consequently, the question arises as to whether sufficient genetic diversity remains within industry stocks to address future needs. However, investigations into allele frequency shifts during domestication and selection in the commercial chicken showed that the differentiation between wild and domestic chickens is mild at most loci, with only a few strongly differentiated regions, potentially due to hard selective sweeps [Qanbari et al., 2019]. A large part of the ancestral variation is still present in domestic chickens. However, commercial lines contain far fewer rare alleles, indicative of a recent bottleneck [Muir et al., 2008]. Interestingly, the alleles with potential functional consequences often lie in the genes of commercial interest and have risen to high frequency by artificial selection [Derks et al., 2018]. One example is a mutation in the chicken thyroid-stimulating hormone receptor (TSHR) which has a beneficial effect on egg-laying [Rubin et al., 2010].

The lower genetic variability in commercial lines becomes a problem if requirements change. Meanwhile, there have been changes in the thinking about animal welfare, and, accordingly, the housing conditions of laying hens. Alternative systems such as the floor-housing, freerange housing, or, at least, cage-housing with enriched cages and more space have replaced the traditional battery cage system. As mentioned above, the adaptation of laying hens to these alternative housing systems is difficult und undesirable side effects developed. Recurrent hybridization with other chicken breeds could alleviate the load in 
bottlenecked domestic species [Wang et al., 2017]. Thus, in modern poultry husbandry, the genetic resources of fancy breeds become more and more important. These breeds represent a resource of genes for future breeding. In terms of biodiversity conservation and utilization, these genetic resources require further identification and evaluation. For several years, researchers have assessed biodiversity at the molecular level in chicken populations [Hillel et al., 2003; Malomane et al., 2019]. The upcoming years will produce more detailed knowledge about fancy breeds and increased efforts to consider old and traditional breeds as a cultural and historical heritage.

\section{Conclusion}

The process of domestication and the process of evolution are very similar since they are the result of selection. However, selective criteria in the wild often remain unclear or are very complex, whereas selection during domestication is man-made and thus clearly identifiable. Investigating domestication or domesticated species/breeds therefore elucidates evolutionary and adaptive processes. And this occurs over a short time period compared to natural evolution, and with animals which are easy to keep and easy to breed.

Whereas domestication of mammals has been intensively studied including brain changes, this is not true in another vertebrate class, birds. Here, the domesticated chicken can act as a model system that combines multiple interacting constructive processes and internal and external inheritance systems, set within an increasingly wellresolved temporal sequence. Apparently, there are classindependent trends and the influence of domestication on brain morphology in birds and mammals is similar. However, despite decades of research about the complex brains and behavior of birds and mammals, the factors responsible for the diversity of brain size and composition are still unclear. In this review, we discussed the value of domestication as a resource for understanding how brain structures can be selected at the species level. Domestic chickens are an example for mosaic brain evolution, where the size of different brain structures evolves independently due to differential selective pressures associated with different tasks [Barton and Harvey, 2000].

Additionally, investigating domestication helps our understanding of correlations between the brain and behavior. Overtyping of special features, in particular, can amplify the knowledge about special defects or diseases. Under the protection of human care, recessive or mal- adaptive features can also be bred out. At first glance, negative alterations like abnormal (brain) morphology are not necessarily associated with a negative influence on (brain) function, which, in turn, is not inevitably linked to a negative impact on animal welfare, i.e., an animal's life per se. The occurrence of strongly pronounced special features can be evaluated by the "handicap principle" which argues in favor of this being an example for "conspicuous consumption" [Zahavi, 1975; Zahavi and Zahavi, 1997]. Extreme breeding forms could also serve as model organisms for diseases or defect mutants. One example is the typical fur "ridge" on the back of the Rhodesian ridgeback dog breed which is associated with a mild form of spina bifida and can lead to complications (infections up to the vertebral canal and the spinal cord) [Salmon Hillbertz et al., 2007]. Another example is the spotted rabbit; special coloring is associated with a megacolon syndrome (Hirschsprung's disease) in homozygous spotted rabbits [Bödeker et al., 1995]. Furthermore, studying crested chickens and ducks provides insights into phenomena like encephaloceles and hydrocephalus [Tao et al., 2020].

Evolution can also be characterized as adaptive alteration in gene frequencies, stabilized by sexual behavior including female-guided mate choice via offspring numbers. This may lead to a new species. Domestication of poultry can lead, in principle, to new species as well, or at least to species which are on the way to a new species. This renders investigating diversity in domestic poultry as a potential model for evolutionary speciation.

If domestication is seen as an evolutionary process and as a huge biological experiment, the question arises, after looking at extreme breeding forms like crested chickens or laying hens, whether this experiment might be loaded with the "run-away effect" described by Fisher [1915, 1930]. During domestication, secondary (nonessential) traits become genetically correlated with the preference of humans. This can lead to the accelerated evolution of exaggerated traits and preferences. It becomes more and more important to not lose sight of the actual breed-specific needs of domestic fowl and to consider not only morphological but also neurological and behavioral adaptations to their man-made ecological niche. It is also important to not ignore the efforts of artificial selection and to honour the long breeding histories of many breeds. Domestication shows an accelerated evolutionary process. It remains a "work in progress," however, and is not yet finished (and probably never will be). Considering and interpreting the results of research into domestic animals will continue to be a principal challenge in the field of evolutionary neuroscience. 


\section{Acknowledgement}

We thank Prof. Gerd Rehkämper for reviewing and improving the manuscript.

\section{Funding Sources}

There was no funding.

\section{Conflict of Interest Statement}

The authors have no conflicts of interest to declare.

\section{Author Contributions}

This paper was written by both authors.

\section{References}

Agnvall B, Bélteky J, Jensen P. Brain size is reduced by selection for tameness in Red Junglefowl- correlated effects in vital organs. Sci Rep. 2017 Jun;7(1):3306.

Airey DC, Castillo-Juarez H, Casella G, Pollak EJ, DeVoogd TJ. Variation in the volume of zebra finch song control nuclei is heritable: developmental and evolutionary implications. Proc Biol Sci. 2000 Oct;267(1457):2099-104.

Augustyniak-Perko M, Frahm HD, Rehkaemper G. Comparative investigations of sensory brain areas in five breeds of the domestic chicken. Acta Biol. 1996;3:75-83.

Baron G, Stephan H, Frahm HD. Comparative Neurobiology in Chirptera. Basel: Birkhäuser; 1996.

Barton NH, Briggs DE, Eisen JA, Goldstein DB, Patel NH. Evolution. New York: Cold Spring Harbor Laboratory Press; 2007.

Barton RA, Harvey PH. Mosaic evolution of brain structure in mammals. Nature. 2000 Jun; 405(6790):1055-8.

Beilharz RG, Nitter G. The missing E: the role of the environment in evolution and animal breeding. J Anim Breed Genet. 1998;115(16):439-53.

Belyaev DK, Plyusnina IZ, Trut LN. Domestication in the silver fox (Vulpus fulvus Desm): changes in physiological boundaries of the sensitive period of primary socialisation. Appl Anim Behav Sci. 1985;13(4):359-70.

Bödeker D, Türck O, Lovén E, Wieberneit D, Wegner W. Pathophysiological and functional aspects of the megacolon-syndrome of homozygous spotted rabbits. Zentralbl Veterinärmed A. 1995 Nov;42(9):549-59.

Boice R. Domestication. Psychol Bull. 1973; 80(3):215-30.

Bosse M. No "doom" in chicken domestication? PLoS Genet. 2019 May;15(5):e1008089.

Bronson RT. Brain weight-body weight scaling in breeds of dogs and cats. Brain Behav Evol. 1979;16(3):227-36.

Brothwell D. Roman evidence of a crested form of domestic fowl, as indicated by a skull showing associated cerebral hernia. J Archaeol Sci. 1979;6(3):291-3.

Campbell DL, de Haas EN, Lee C. A review of environmental enrichment for laying hens during rearing in relation to their behavioral and physiological development. Poult Sci. 2019 Jan;98(1):9-28.
Campbell DL, Talk AC, Loh ZA, Dyall TR, Lee C. Spatial Cognition and Range Use in FreeRange Laying Hens. Animals (Basel). 2018 Feb;8(2):E26

Castiglione S, Serio C, Piccolo M, Mondanaro A, Melchionna M, Di Febbraro M, et al. The influence of domestication, insularity and sociality on the tempo and mode of brain size evolution in mammals. Biol J Linn Soc Lond. 2021;132(1):221-31.

Charlesworth D, Willis JH. The genetics of inbreeding depression. Nat Rev Genet. 2009 Nov;10(11):783-96.

Clutton-Brock J. A natural history of domesticated mammals. London: Cambridge University Press; 1987.

Clutton-Brock TH, Harvey PH. Primates, brains and ecology. J Zool. 1980;190(3):309-23.

Cnotka J, Frahm HD, Mpotsaris A, Rehkämper G. Motor incoordination, intracranial fat bodies, and breeding strategy in Crested ducks (Anas platyrhynchos f.d.). Poult Sci. 2007 Sep; 86(9):1850-5.

Cnotka J, Tiemann I, Frahm HD, Rehkämper G. Unusual brain composition in Crested Ducks (Anas platyrhynchos f.d.)-including its effect on behavior and genetic transmission. Brain Res Bull. 2008 Jun;76(3):324-8.

Coyne JA, Orr AH. Speciation. Massachusetts: Sinauer Associates Inc; 2004.

Darwin C. The variation in animals and plants under domestication. London: John Murray; 1868.

Derks MF, Megens HJ, Bosse M, Visscher J, Peeters K, Bink MC, et al. A survey of functional genomic variation in domesticated chickens. Genet Sel Evol. 2018 Apr;50(1):17.

Diamond J. Evolution, consequences and future of plant and animal domestication. Nature. 2002 Aug;418(6898):700-7.

Diamond MC. Response of the brain to enrichment. An Acad Bras Cienc. 2001 Jun; 73(2):211-20.

Dubois E. Über die Abhängigkeit des Hirngewichts von der Körpermasse bei den Säugetieren. Arctic Anthropol. 1897;25:1-28.

Dudde A, Krause ET, Matthews LR, Schrader L. More than Eggs - Relationship between Productivity and Learning in Laying Hens. Front Psychol. 2018 Oct;9:2000.

Ebinger P, Löhmer R. A volumetric comparison of brains between greylag geese (Anser anser
L.) and domestic geese. J Hirnforsch. 1987;28(3):291-9.

Ebinger P. Alterations of brain size and behaviour in domesticated birds. Acta Biol Benrodis. 1996;3.

Ebinger P, Löhmer R. Comparative quantitative investigations on brains of rock doves, domestic and urban pigeons (Columba l. livia). J Zool Syst Evol Res. 1984;22:136-45.

Ebinger P. Domestication and plasticity of brain organization in mallards (Anas platyrhynchos). Brain Behav Evol. 1995;45(5):286-300.

Ebinger P. Vergleichend-quantitative Untersuchungen an Wild- und Laborratten. Z Tierzücht Züchtungsbiol. 1972;89(1-4):34-57.

Ebinger P. Zur Hirn- Körpergewichtsbeziehung bei Wölfen und Haushunden sowie Haushundrassen. Z Säugetierkd. 1980;45:148-53.

Ekarius C. Storey's Illustrated Guide to Poultry Breeds. North Adams (MA): Storey Books; 2007.

Eusemann BK, Baulain U, Schrader L, ThöneReineke C, Patt A, Petow S. Radiographic examination of keel bone damage in living laying hens of different strains kept in two housing systems. PLoS One. 2018 May;13(5): e0194974.

Finlay BL, Hinz F, Darlington RB. Mapping behavioural evolution onto brain evolution: the strategic roles of conserved organization in individuals and species. Philos Trans R Soc Lond B Biol Sci. 2011 Jul;366(1574):2111-23.

Fisher RA. The evolution of sexual preference. Eugen Rev. 1915 Oct;7(3):184-92.

Fisher RA. The Genetical Theory of Natural Selection. Oxford, UK: Clarendon Press; 1930. https://doi.org/10.5962/bhl.title.27468.

Frahm HD, Rehkämper G. Allometric comparison of the brain and brain structures in the white crested polish chicken with uncrested domestic chicken breeds. Brain Behav Evol. 1998a;52(6):292-307.

Frahm HD, Rehkämper G. Volumetric comparison of auditory brain nuclei in ear-tufted Araucanas with those in other chicken breeds. J Hirnforsch. 1998b;39(1):37-44.

Frantz LA, Schraiber JG, Madsen O, Megens HJ, Cagan A, Bosse M, et al. Evidence of longterm gene flow and selection during domestication from analyses of Eurasian wild and domestic pig genomes. Nat Genet. 2015 Oct;47(10):1141-8. 
Frick H, Nord HJ. Domestikation und Hirngewicht. Anat Anz. 1963 Nov;113:307-16.

Fumihito A, Miyake T, Takada M, Shingu R, Endo T, Gojobori T, et al. Monophyletic origin and unique dispersal patterns of domestic fowls. Proc Natl Acad Sci USA. 1996 Jun;93(13):6792-5.

Güntürkün $\mathrm{O}$, Bugnyar T. Cognition without Cortex. Trends Cogn Sci. 2016 Apr;20(4):291303.

Gupta SK, Behera K, Pradhan CR, Mandal AK, Sethy K, Behera D, et al. Studies of the macroscopic and microscopic morphology (hippocampus) of brain in Vencobb broiler. Vet World. 2016 May;9(5):507-11.

Haase E, Otto C, Murbach H. Brain weight in homing and 'non-homing' pigeons. Experientia. 1977 May;33(5):606-7.

Hager R, Lu L, Rosen GD, Williams RW. Genetic architecture supports mosaic brain evolution and independent brain-body size regulation. Nat Commun. 2012;3(1):1079.

Hale EB. Domestication and the evolution of behaviour. In: Hafez ES, editor. The behaviour of domestic animals. London: Baillière, Tindall and Cassell; 1969. pp. 22-42.

Harvey P. Allometric analysis and brain size. In: Jerisson HJ, Jerisson I, editors. Intelligence and Evolutionary Biology. NATO ASI Series G17. Berlin: Springer; 1988. pp. 199-210.

Hemmer H. Domestication: the decline of environmental appreciation. Cambridge: Cambridge University Press; 1983.

Henriksen R, Johnsson M, Andersson L, Jensen P, Wright $\mathrm{D}$. The domesticated brain: genetics of brain mass and brain structure in an avian species. Sci Rep. 2016 Sep;6(1):34031.

Herre W, Röhrs M. Haustiere-zoologisch gesehen. Stuttgart: Gustav Fischer Verlag; 1990. https://doi.org/10.1007/978-3-642-39394-5.

Hewlett SE, Zeinstra EC, van Eerdenburg FJ, Rodenburg T, van Kooten PJ, van der Staay F, et al. Hypothalamic vasotocin and tyrosine hydroxylase levels following maternal care and selection for low mortality in laying hens. BMC Vet Res. 2014 Jul;10(1):167.

Hillel J, Groenen MA, Tixier-Boichard M, Korol AB, David L, Kirzhner VM, et al. Biodiversity of 52 chicken populations assessed by microsatellite typing of DNA pools. Genet Sel Evol. 2003 Sep-Oct;35(5):533-57.

Höglund A, Strempfl K, Fogelholm J, Wright D, Henriksen R. The genetic regulation of size variation in the transcriptome of the cerebrum in the chicken and its role in domestication and brain size evolution. BMC Genomics. 2020 Jul;21(1):518.

Ito M. The cerebellum and neural control. New York: Raven; 1984

Jackson S, Diamond J. Metabolic and Digestive Responses to Artificial Selection in Chickens. Evolution. 1996;50(4):1638-50.

Kawabe S, Tsunekawa N, Kudo K, Tirawattanawanich $\mathrm{C}$, Akishinonomiya $\mathrm{F}$, Endo $\mathrm{H}$. Morphological variation in brain through domestication of fowl. J Anat. 2017 Aug;231(2):287-97.
Komiyama T, Ikeo K, Gojobori T. Where is the origin of the Japanese gamecocks? Gene. 2003 Oct;317(1-2):195-202.

Komiyama T, Yoshikawa M, Yokoyama K, Kobayashi $\mathrm{H}$. Analysis of the source of aggressiveness in gamecocks. Sci Rep. 2020 Apr;10(1):7005.

Krause ET, Naguib M, Petow S. Effects of intrahippocampal D-AP5 injections on one trial passive avoidance learning in adult laying hens (Gallus gallus domesticus). Acta Neurobiol Exp (Wars). 2008;68(4):494-501.

Kruska D, Stephan H. Volumetric comparison of allocortical brain centers in wild and domestic pigs. Acta Anat (Basel). 1973;84(3):387-415. German.

Kruska D. Volumetric comparison of various visual centers in the brains of wild boars and domestic pigs. Z Anat Entwicklungsgesch. 1972;138(3):265-82. German.

Kruska D. Mammalian domestication and its effect on brain structure and behavior. In: Jerisson $\mathrm{HJ}$, Jerisson I, editors. Intelligence and Evolutionary Biology. NATO ASI Series G17. Berlin: Springer; 1988. pp. 211-50.

Kruska DC. On the evolutionary significance of encephalization in some eutherian mammals: effects of adaptive radiation, domestication, and feralization. Brain Behav Evol. 2005; 65(2):73-108.

Kruska DC. The effects of domestication on brain size. In: Kaas JH, editor. Evolution of Nervous Systems. Academic Press; 2007. pp. 143-53.

Lay DC Jr, Fulton RM, Hester PY, Karcher DM, Kjaer JB, Mench JA, et al. Hen welfare in different housing systems. Poult Sci. 2011 Jan;90(1):278-94.

Lynch M, Ackerman MS, Gout JF, Long H, Sung W, Thomas WK, et al. Genetic drift, selection and the evolution of the mutation rate. Nat Rev Genet. 2016 Oct;17(11):704-14.

Malomane DK, Simianer H, Weigend A, Reimer C, Schmitt AO, Weigend S. The SYNBREED chicken diversity panel: a global resource to assess chicken diversity at high genomic resolution. BMC Genomics. 2019 May;20(1):345.

Mann MD, Frank LG, Glickman SE, Towe AL. Brain and body size relations among spotted hyenas (Crocuta crocuta). Brain Behav Evol. 2018;92:82-95.

Mayr E. Animal species and evolution. Harvard (Mass.): The Belknap Press; 1963. https://doi. org/10.4159/harvard.9780674865327.

Mehlhorn J, Petow S. Smaller brains in laying hens: new insights into the influence of pure breeding and housing conditions on brain size and brain composition. Poult Sci. 2020 Jul;99(7):3319-27.

Mehlhorn J, Rehkaemper G. Brain alterations, their impact on behavior and breeding strategy in Crested Ducks (Anas platyrhynchos f. d.). Arch Geflugelkd. 2010 Jul;74(3):203-9.

Mehlhorn J, Rehkämper G. Some remarks on bird's brain and behavior under the constraints of domestication. ISRN. 2013. DOI: 10.5402/2013/460580.
Miao YW, Peng MS, Wu GS, Ouyang YN, Yang $\mathrm{ZY}, \mathrm{Yu} \mathrm{N}$, et al. Chicken domestication: an updated perspective based on mitochondrial genomes. Heredity. 2013 Mar;110(3):277-82.

Mohammed AH, Zhu SW, Darmopil S, HjerlingLeffler J, Ernfors P, Winblad B, et al. Environmental enrichment and the brain. Prog Brain Res. 2002;138:109-33.

Möller H. Zur Kenntnis der Größenabhängigkeit von Hirnmerkmalen bei Hauskaninchen. Zool Jb Anat. 1975;94:161-99.

Muir WM, Wong GK, Zhang Y, Wang J, Groenen MA, Crooijmans RP, et al. Genome-wide assessment of worldwide chicken SNP genetic diversity indicates significant absence of rare alleles in commercial breeds. Proc Natl Acad Sci USA. 2008 Nov;105(45):17312-7.

Nordquist RE, Zeinstra EC, Dougherty A, Riber AB. Effects of Dark Brooder Rearing and Age on Hypothalamic Vasotocin and Feather Corticosterone Levels in Laying Hens. Front Vet Sci. 2020 Jan; 7:19.

Nordquist RE, Zeinstra EC, Rodenburg TB, van der Staay FJ. Effects of maternal care and selection for low mortality on tyrosine hydroxylase concentrations and cell soma size in hippocampus and nidopallium caudolaterale in adult laying hen. J Anim Sci. 2013 Jan;91(1):137-46.

Pabilonia MS, Somes RG Jr. The embryonic development of ear-tufts and associated structural head and neck abnormalities of the Araucana fowl. Poult Sci. 1983 Aug;62(8):1539-42.

Patzke N, Ocklenburg S, van der Staay FJ, Güntürkün O, Manns M. Consequences of different housing conditions on brain morphology in laying hens. J Chem Neuroanat. 2009 May;37(3):141-8.

Price EO, editor. Animal domestication and behavior. Wallingford: CAB International; 2002.

Price EO. Behavioral development in animals undergoing domestication. Appl Anim Behav Sci. 1999;65(3):245-71.

Qanbari S, Rubin CJ, Maqbool K, Weigend S, Weigend A, Geibel J, et al. Genetics of adaptation in modern chicken. PLoS Genet. 2019 Apr;15(4):e1007989.

Rehkämper G, Frahm HD, Cnotka J. Mosaic evolution and adaptive brain component alteration under domestication seen on the background of evolutionary theory. Brain Behav Evol. 2008;71(2):115-26.

Rehkämper G, Haase E, Frahm HD. Allometric comparison of brain weight and brain structure volumes in different breeds of the domestic pigeon, Columba livia f.d. (fantails, homing pigeons, strassers). Brain Behav Evol. 1988;31(3):141-9.

Rehkämper G, Kart E, Frahm HD, Werner CW. Discontinuous variability of brain composition among domestic chicken breeds. Brain Behav Evol. 2003;61(2):59-69.

Reiner A, Perkel DJ, Bruce LL, Butler AB, Csillag A, Kuenzel W, et al.; Avian Brain Nomenclature Forum. Revised nomenclature for avian telencephalon and some related brainstem nuclei. J Comp Neurol. 2004 May;473(3):377-414. 
Rensch B. Das prinzip geographischer Rassenkreise und das Problem der Artbildung. Berlin: Bortraeger; 1929.

Rodenburg TB, Komen H, Ellen ED, Koen A, Uitdehaag J, van Arendonk AM. Selection method and early-life history affect behavioural development, feather pecking and cannibalism in laying hens: A review. Appl Anim Behav Sci. 2008;110(3-4):217-28.

Rosenzweig MR, Bennett EL. Psychobiology of plasticity: effects of training and experience on brain and behavior. Behav Brain Res. 1996 Jun;78(1):57-65.

Rosenzweig MR. Effects of differential experience on the brain and behavior. Dev Neuropsychol. 2003;24(2-3):523-40.

Rubin CJ, Zody MC, Eriksson J, Meadows JR, Sherwood E, Webster MT, et al. Whole-genome resequencing reveals loci under selection during chicken domestication. Nature. 2010 Mar;464(7288):587-91.

Salmon Hillbertz NH, Isaksson M, Karlsson EK, Hellmén E, Pielberg GR, Savolainen P, et al. Duplication of FGF3, FGF4, FGF19 and ORAOV1 causes hair ridge and predisposition to dermoid sinus in Ridgeback dogs. Nat Genet. 2007 Nov;39(11):1318-20.

Sheppy A. The colour of domestication and the designer chicken. Opt Laser Technol. 2011;43(2):295-301.

Simons YB, Sella G. The impact of recent population history on the deleterious mutation load in humans and close evolutionary relatives. Curr Opin Genet Dev. 2016 Dec;41:150-8.

Snell O. Die Abhängigkeit des Hirngewichts von dem Körpergewicht und den geistigen Fähigkeiten. Arch Psychiatr Nervenkr. 1892;23(2):436-46.

Sossinka R. Domestication in birds. In: Farner DS, King JR, Parkes KC, editors. Avian Biology. London: Academic Press; 1982. pp. 373403.

Stange M, Núñez-León D, Sánchez-Villagra MR, Jensen P, Wilson LA. Morphological variation under domestication: how variable are chickens? R Soc Open Sci. 2018 Aug; 5(8):180993.
Stephan H, Baron G, Frahm HD. Comparative size of brains and brain components. In: Steklis HD, Erwin J, editors. Comparative Primate Biology. Volume 4. New York: Lissauer; 1988. pp. 1-38.

Stephan H, Baron G, Frahm HD. Insectivora New York: Springer; 1991. https://doi. org/10.1007/978-1-4613-9124-1.

Stephan H, Frahm H, Baron G. New and revised data on volumes of brain structures in insectivores and primates. Folia Primatol (Basel). 1981;35(1):1-29.

Tao Y, Zhou X, Zheng X, Li S, Mou C. Deciphering the forebrain disorder in a chicken model of cerebral hernia. Genes (Basel). 2020;11(9):1008

Tiemann I, Rehkämper G. Rasseunterschiede bei Haushühnern (Gallus gallus f.d.) bei klassischer und operanter Konditionierung in der Skinnerbox. Acta Biol Benrodis. 2007;13:23140.

Tiemann I, Rehkämper G. Breed-specific companions-inter-individual distances reflect isolating mechanisms within domesticated chickens (Gallus gallus f.d.). Brain Res Bull. 2008 Jun;76(3):300-3.

Tiemann I, Rehkämper G. Effect of artificial selection on female choice among domesticated chickens Gallus gallus f.d. Poult Sci. 2009 Sep;88(9):1948-54.

Tiemann I, Rehkämper G. Evolutionary pets: offspring numbers reveal speciation process in domesticated chickens. PLoS One. 2012;7(8):e41453.

Tixier-Boichard M, Bed'hom B, Rognon X. Chicken domestication: from archeology to genomics. C R Biol. 2011 Mar;334(3):197204.

Towe AL, Mann MD. Habitat-related variations in brain and body size of pocket gophers. J Hirnforsch. 1995;36(2):195-201.

Verdiglione R, Rizzi C. A morphometrical study on the skull of Padovana chicken. Ital J Anim Sci. 2018;17(3):785-96.

Wang J, Santiago E, Caballero A. Prediction and estimation of effective population size. Heredity. 2016 Oct;117(4):193-206.
Wang L, Beissinger TM, Lorant A, Ross-Ibarra C, Ross-Ibarra J, Hufford MB. The interplay of demography and selection during maize domestication and expansion. Genome Biol. 2017 Nov; 18(1):215.

Wang Y, Gao Y, Imsland F, Gu X, Feng C, Liu R, et al. The crest phenotype in chicken is associated with ectopic expression of HOXC8 in cranial skin. PLoS One. 2012;7(4):e34012.

Weeks CA, Lambton SL, Williams AG. Implications for Welfare, Productivity and Sustainability of the Variation in Reported Levels of Mortality for Laying Hen Flocks Kept in Different Housing Systems: A Meta-Analysis of Ten Studies. PLoS One. 2016 Jan;11(1):e0146394.

Weidemann W. Die Beziehung von Hirngewicht und Körpergewicht bei Wölfen und Pudeln sowie deren Kreuzungsgenerationen N1 und N2. Z Säugetierkd. 1979;35:238-47.

Whitehead CC. Overview of bone biology in the egg-laying hen. Poult Sci. 2004 Feb;83(2):193-

Wilkins AS, Wrangham RW, Fitch WT. The "domestication syndrome" in mammals: a unified explanation based on neural crest cell behavior and genetics. Genetics. 2014 Jul;197(3):795-808.

Willemet R. Reconsidering the evolution of brain, cognition, and behavior in birds and mammals. Front Psychol. 2013 Jul;4:396.

Wright S. The relationship of livestock breeding to theories of evolution. J Anim Sci. 1978;46(5):1192-200.

Yoshimura K, Kinoshita K, Mizutani M, Matsuda Y, Saito N. Inheritance and developmental pattern of cerebral hernia in the crested Polish chicken. J Exp Zoolog B Mol Dev Evol. 2012 Dec;318(8):613-20.

Zahavi A, Zahavi A. The handicap principle: a missing piece of Darwin's puzzle. New York: Oxford University Press; 1997.

Zahavi A. Mate selection-a selection for a handicap. J Theor Biol. 1975 Sep;53(1):205-14.

Zeder MA. Domestication as a model system for the extended evolutionary synthesis. Interface Focus. 2017 Oct; 7(5):20160133.

Zeder MA. Why evolutionary biology needs anthropology: evaluating core assumptions of the extended evolutionary synthesis. Evol Anthropol. 2018 Nov;27(6):267-84. 